\title{
Development of Designing Criteria in Children's Urban Play Space in Iran- Review of Literature
}

\author{
Noura Marouf ${ }^{1,2}$, Adi Irfan Che-Ani ${ }^{1}$, Norngainy Mohd Tawil ${ }^{1}$, Suhana Johar $^{1} \&$ Mazlan Mohd Tahir ${ }^{1}$ \\ ${ }^{1}$ Department of Architecture, Faculty of Engineering and Built Environment, Universiti Kebangsaan Malaysia \\ (UKM), 43600 UKM Bangi, Malaysia \\ ${ }^{2}$ Islamic Azad Uuniversity, Gorgan Branch, Iran \\ Correspondence: Noura Marouf, Department of Architecture, Faculty of Engineering and Built Environment, \\ Universiti Kebangsaan Malaysia (UKM), 43600 UKM Bangi, Malaysia. Tel: 60-10-897-8906. E-mail: \\ noura.marouf@gmail.com
}

Received: December 27, 2014 Accepted: January 14, 2015 Online Published: March 30, 2015

doi:10.5539/jsd.v8n2p113 URL: http://dx.doi.org/10.5539/jsd.v8n2p113

\begin{abstract}
One of the most significant issues related to urban public design is considering outdoor spaces for children to play. Children need to see their environment as a part of their life and learn to protect it. Furthermore, they develop social, emotional, and physical skills by playing outdoors. In some developing countries such as Iran, limited knowledge exists about the state of outdoor play areas for children in cities. This study highlights the need for planners and other land managers to consider the critical importance of the urban environment for play activities of children and its current status in Iran. Literature, studies, opinions and ideas on the value of play and outdoors for children in cities and the limitations of their outdoor play is explored; the issues and points obtained from the literature are analyzed. And the need for further research with children and rethinking for the allocation and design of children's open space in Tehran is highlighted. Consequently, the criteria to consider children's play spaces in city of Tehran are proposed. Accessibility, local government involvement, knowledge sharing, appropriate playground design and accounting on children's voice and view in design process are some criteria which are recommended to promote children's open space and outdoor play area in Tehran.
\end{abstract}

Keywords: children, outdoor play, urban open space, playground

\section{Introduction}

\subsection{Significance of Children's Outdoor Play}

Play is defined as a variety of activities and behaviors of children in their free time (Pellegrini 2005), consisting of a considerable proportion of opportunities for physical activity (Pellegrini and Smith 1998; Rippe et al. 1993). Despite the difficulty of defining the term because of the complexity of behavior (Powell 2009), play is generally associated with fun, enjoyable, freely chosen, inherently motivated and flexible activities and behaviors (Armitage 2001; Pellegrini and Smith 1998; Titman and McGill 1992). Play is a vital aspect of child development along with emotional, social, physical, and cognitive skills.

Many studies considered the various aspects of outdoor play that influence child development. Research shows that by experimenting, children promote their own physical fitness and social interactions as well as improve their self-esteem (Bartlett, 1999a). Outdoor play provides many opportunities for social learning and being more public. As some children geographers stated outdoor play, "is crucial because it is the primary mechanism through which children become acquainted with their environment" (Valentine, 2004, 74). Through play, children could experience and learn motor skills, communicate with others, solve problems, exercise creativity, and think logically (Hart 2002; Hughes 1990; Bartlett 1999; Barnett 1990; Mergen 1975; Chawla and UNESCO 2002; Chawla and Heft 2002; Beard and Ragheb 1980). In addition, children enhance their conversational and organizational skills, as well as their sense of adventure and exploration when they play with their peers (Moore 1990). However, the literature indicates that children need to play outdoors to completely develop various aspects of their personality, including social, emotional, cognitive, and physical skills.

\subsection{Indoor Children}

Although play and such activities are vital for the development of children, studies show that at the present time, 
children seldom experience outdoor play. Instead, they spend most of their time inside buildings or vehicles, which leads to the commodification of the childhood (Wridt 2004). Some other studies show that children spend a significant part of their lives in the virtual world such as television and computers (Zaradic and Pergams 2007).

Moreover, the Benesse Educational Research Center in Tokyo (1999, cited in Clements, 2004) conducted a survey to discover the play behaviors of children in metropolitan and rural areas in Japan. The results show that 40 percent of the children preferred to play indoors rather than outdoors, and 70 percent of the participants stated watching television as the most popular activity of interest in their free time.

Clements (2004) examined the status of outdoor play and found more regular indoor activities than outdoor activities. According to this survey, more than 70 percent of children spend their time watching television; playing computer, video, and board games; and reading. Similarly, studies showed that children in the United States, England, and Australia spend more than four hours per day viewing television (Dietze and Crossley 2000; Chen 1994; Townsend and Taub 2004; Andersen et al. 1998). Other recent studies also discovered that children who spend more time sitting in a classroom without having breaks for physical activities tend to be more sedentary at home and engaged in television viewing for extended hours (Dale et al. 2000).

Compared with indoor spaces, the outdoor environment provides opportunities for investigation, exploration, and practice of various skills, which contributes to child development. Furthermore, friendships among children do not happen mainly in a cooperative setting in enclosed places but by playing outside. A consequence of the indoor-oriented behavior of children is the increasing rates of obesity and sedentary lifestyles, which are undoubtedly harmful to human health (CDC, 2008; CDC, 2009).

\subsection{Open Spaces for Children}

Since birth, every child is affected by his or her surroundings. Whether limiting or helping the child's health and development, the influence of surrounding environments lasts a lifetime. Regarding the importance of outdoor play for children, the environment where it takes place is also significant. The outdoor environment influences the different aspects of child development by providing opportunities for free or unstructured play every day. As Moore (1987; 63) states: "the environment involves physical components that have measurable impacts on cognitive development". Thus, the child needs various environmental experiences for healthy development. According to Ward (Ward 1978), "You cannot keep your children under house arrest. If you attempt to do so, they will escape, and if they don't escape, they will undoubtedly have been deprived of vital environmental experiences".

In the modern world, children have both gained and missed the benefits of physical activity. Although outdoor play is important for children's health, low levels of physical activity have been reported in many countries (Tomkinson et al. 2003; Carlin et al. 1997). For example, researches showed that 20-25 percent of Australian adolescents have insufficient activity to enjoy health gains (Booth 2000). Similarly, in the US and the UK, low levels of physical activity have been reported (CDC 2003; Reilly et al. 2004). Consequently, increased levels of obesity (Wing et al. 2001; Vincent et al. 2003), diabetes, and other diseases caused by sedentary living (Zimmet et al. 1997; Wing et al. 2001; Trost 2005) provide further rationale for investigating the physical activities of children.

\section{Children as an Urban Issue}

In one hand, compared with designers in the past, designers today pay significantly more attention to planning appropriate playgrounds. And on the other hand, with the increased number of automobiles, the desire of city planners to improve the speed and efficiency of traffic has affected cities through the decline of pedestrian walkways and places for children to play near their homes. "However, in the face of urbanization, cities are becoming less accessible to children, less equipped to cater to their needs and to foster appropriate development" (Gunawardena et al., 2003 cited in Memik 2004). Today, communities experiencing urbanization face different issues and consequences of population growth, housing deficiency, unemployment, sanitation, and security, pushing concerns about children's play out of the public debate on policy priorities (Bartlett et al. 1999).

One of the main goals of the urban development is preserving the environment for the future generation. In this regard, instead of only considering planning issues, focusing specifically on land use is also necessary. Planners have not adequately directed the needs, views, and opportunities for children in designing friendly urban environments because they are struggling with the task of considering children in city development and finding ways to maintain sufficient resources for this purpose. For instance, in the US and the UK, the ratio of recreational areas to the population is six acres and ten acres per 1000 people, respectively. However, in some densely populated countries such as Bangladesh and Singapore, this ratio is only 0.56 acres and 2.5 acres per 
1000 people, respectively, far below the efficient rates (Siddiqui 1990). Even in modern and unpopulated countries, some evidence of a reduction of urban open space for children is also found. For instance, with the diminishing public domain and backyards in Australia, the value of outdoor environments increased (Hall 2010). Similarly, in many Polish cities, problems such as reduction of public green spaces, growth of traffic, pollution, and crime create a child-unfriendly environment (Boesen 1999; Risotto 2002; Sawyer 2002). Moreover, in a city such as New York, despite being the location of first playgrounds in the world, children have shown minimal interest in them (Ward 1978). These statistics prove the clear disconnection between the planning and design methods of public spaces for children, which establish their social and psychological learning stimulations.

\subsection{Open Spaces in Tehran}

Statistics show that Tehran, with 146 people per hectare of built-up area, is a densely populated city compared with other cities by world standards (Bertaud 2003). In addition to a natural increase of the population, a large number of migrants to Tehran from rural areas and other Iranian cities is observed in the statistics. Whereas the population of Tehran in 1956 was only 1.5 million, it grew sharply to 8.5 million in 2011 (Tehran-Municipality 2011).

Saremi et al. (2012) predicted that the population of Tehran would reach approximately 12.5 million people in 20 years. As a result, the city has not only spread out physically, but it has also gradually consumed open spaces, including playgrounds, parks, and green spaces. He stated that, 40 years ago, many uncontrolled building constructions operated, and some green, open, and sports spaces in Tehran were reduced. In addition, the rate of the conversion of green and open areas to developed ones accelerated during this period. According to studies, from 2004 to 2005, over 600 open or green spaces in Tehran were transformed to residential or commercial areas (Behzadfar 2009). Table 1 shows the reduction of green spaces in Tehran during the past 20 years (Talebi and Ardakani 2011).

Table1. Changes in the green area of Tehran in square meter per person (1988-2009)

\begin{tabular}{llll}
\hline Year & Population (person) & Total green area $(\mathrm{Ha})$ & $\begin{array}{l}\text { Green area per capita } \\
\text { (Square meter per person) }\end{array}$ \\
\hline 1988 & 6042584 & 13041.630 & 21.58 \\
2009 & 7962429 & 14162.850 & 17.78 \\
\hline
\end{tabular}

Saremi et al. (2012) proposed a prediction model for the rate of decreasing open and green spaces in Tehran (Figure 1).

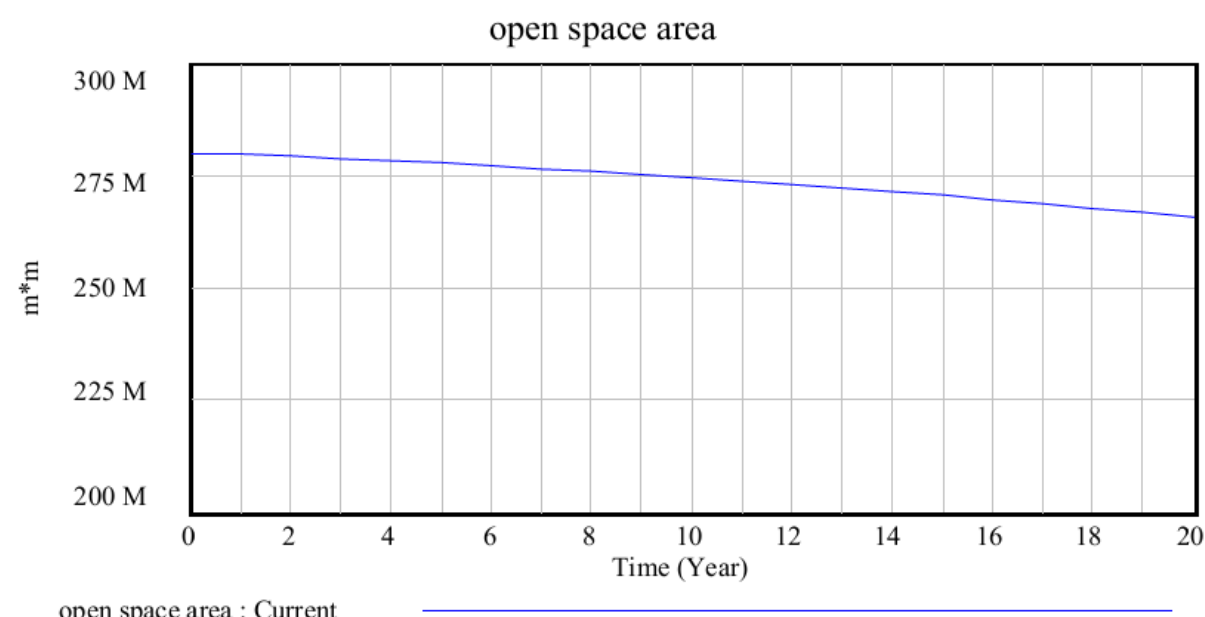

Figure1. Changing predication of urban open space reduction during the 20-year period

The figure 1 shows that while the population of children is growing in cities, the places for their play are shrinking with time. Consequently, when the open spaces are gradually removed, children in the city would have 
no other desirable place to play in. Obviously, without sufficient outdoor spaces for play, children will miss the opportunities for outdoor play progressively, and as members of society, children will be unable to obtain the benefits of social and emotional development through outdoor play. In this context, children have to compete with adults for consideration in economic policies and strategies, a condition that occurs in land use in cities, especially metropolitan areas.

A main duty of the urban planner is the regulation and control of land use. Land-use policy and decision making are limited by broader government policies dictated by the laws and regulations issued by the government. Exploring the development of positive policies is necessary for planning in cities such as Tehran.

\subsection{Child-friendly Urban Landscape}

Planners have recently emphasized the issue of the vulnerability of children in city planning, so that they can claim their rightful place in the city. According to planners, emphasizing equal opportunities for children in cities is an integral part of planning, which should also consider their needs. Integrating the needs of children into landscape design and the planning process can be a well-established and accepted requirement by educators and other professionals whose work mainly influences the lives of children. In fact, the lack of policy attention to the needs of children is evident in the near omission of discussions about the needs of children in the planning literature on Iranian cities. Creating child-friendly cities can be useful for the entire society. The type of landscape in cities should be considered because both children and adults value enjoyable landscapes. In an ideal world, creating specific areas for children would be unnecessary; the process itself can be productive because it considers children in the community and society as having equal rights as adults.

\section{Some Considerations on Open Spaces}

\subsection{Recognition of Children's Rights as Users of the Environment}

Children are an integral part of a wider urban society, and individuals responsible for land use in cities should consider the needs and rights of children as an important part of the planning process. Outdoor activities are not only recognized as a need but also as a fundamental right of children (Moore 1987). Several conventions and conferences on children's rights in cities have been held, such as the following:

Mayors Defenders of Children Initiative in Dakar, Senegal, 1992

United Nations Convention on the Rights of the Child (CRC), 1989

The CRC identifies a child as a person whose age is under 18 years old. The purpose of this convention is to make families, institutions, and governments aware of their responsibilities in the rights of children.

In the last decades, a significant number of international conferences drafted the Local Agenda 21 (the program of action of the UN Conference on Environment and Development 1992), the Habitat Agenda (Second UN Conference on Human Settlements 1996), and "A World Fit for Children" (the document produced at the UN Special Session on Children in New York in 2002), which plans to make cities more adaptable to the needs and rights of children (Riggio 2002).

Local Agenda 21 is an excellent opportunity to develop new ways of working with children and positive environmental initiatives that will benefit children. It contributes to the development of enrichment and policies. Steps can be taken by everyone who makes decisions on land use to fulfill the play activities of children in wider environments, especially in the provision of open spaces. Children's participation in frequent, free-spirited play with their peers is best for their bodies, minds, and spirits. Thus, creating spaces where they can play spontaneously on a daily basis is necessary to address the issue at hand. In addition, children's rights should be considered in the usual planning policies of cities.

\subsection{Evaluating Open Spaces}

Evidence-based data or research work is lacking on the evaluation of existing outdoor play spaces in many cities in the world, such as Tehran. Despite the greater use and ubiquity of playgrounds in developing countries, most of the available studies and papers were written in developed countries. As more playground users are found in the urban parks of developing countries than in those of developed countries, evaluating and examining current playground environments and proposing suitable environmental planning are significantly necessary in developing countries. Such issues are important for a city such as Tehran, which is a strategic metropolis in Iran. Planners need to address the issue of open spaces for children as well as re-examine their attitudes toward these landscapes. Local government bodies, such as city councils, should also exert effort to develop and improve these environments. 


\subsection{Child Participation as a Component}

Although public participation is an accepted principle for planners, limited evidence seems to suggest that planners seriously involve children in planning decisions, even in instances where the children are at the center of the decisions. Ward argues that "the world of the child is a sphere of the socially weak and is ruthlessly manipulated" (1978; 203). However, the research conducted by Coffin and Williams (1989) shows that children have well-defined ideas about a play space that is valuable, and they also experience and understand the environment in which they live. Thus, considering the role of children is significant in improving their environment.

\subsection{Considering Barriers to Open Space Use by Children}

Today's indoor-oriented child in the city has a limited chance of attending peer groups in outdoor environments. Given the small area of modern urban houses, most of which are apartments without wide spaces such as yards for the outdoor play of children, using public areas as parks and playgrounds seems necessary now more than ever. According to the literature, a variety of factors mostly limit the opportunities for outdoor play and activities in outdoor places for children in cities, including the following:

Safety: Various issues have been addressed in the literature. A number of risk factors are faced by children in cities, such as increasing traffic, stray dogs, standing water, and open drains (Ahmed 2005). In the case of Iran, many reports are documented about the lack of safety in the play environments of children. For example, Jafari et al. (2011) examined the safety of children in local-regional parks of Tehran. They found that nearly 70 percent of the playground equipment in parks could be potentially dangerous and may lead to serious injuries in children. Similarly, Rehmani (2008) discovered that playgrounds, after home environments, are the second most frequent location of injuries during play, accounting for 30 percent of the injuries in Pakistan. Playground safety seems to be a significant issue in preparing proper standards because the injuries of children in playgrounds are more common in developing countries than in developed ones.

Parents'concerns: The views of parents about the physical outdoor environment can influence their decisions to allow their children to play outside alone. Studies show that one of the major reasons for keeping children inside houses is the fear of their parents about moral injury or physical assault (e.g., exposure to anti-social behavior, kidnapping, or sexual molestation) that may exist outdoors, especially for girls (Blakely 1994; McKendrick et al. 2000). Jafari et al. (2011) discovered that the safety issues have caused anxiety among mothers about letting their children play in the urban parks of Tehran. Amiri et al. (2013) found that only approximately one-third of the parents in Tehran had a positive judgment about the safety of their neighborhood where their children usually play after school. Consequently, the anxiety of parents has caused many children to miss the opportunity to experience outdoor play.

New patterns of family life: Parents work all day to pay for living costs, and they have limited time to bring their children outdoors to play. As parents do not have enough time and energy to play with their children, the children spend more time in organized indoor programs. From another perspective, children exert excessive effort to study and have academic achievements, which reduces their time for outdoor play (White and Stoecklin 1998); this experience may have a negative effect on child development.

Technology: Nowadays, because of the attractiveness of technological innovations, the play behavior of children has changed and become indoor-oriented. "Children have little time for free play anymore. And when children do have free time it's often spent inside in front of the television or computers" (White and Stoecklin 1998). To address their fear for their children's safety outdoors, parents provide them with indoor play facilities (Hart 1992). Consequently, children are not only disconnected from the natural setting and miss the advantages of such an environment, but are also found to have reduced critical thinking as a result of playing computer games and watching television (Lobo and Olson 2000).

Poor design: After modernization that leads to the creation of formal spaces for the play activities of children, desirable playgrounds are starting to be provided by designers. However, because the needs of the children who play in these kinds of places are unmet, some children prefer to seek their own informal places to play. Consequently, as play is a vital component of the lives of children, they may consider any informal place to play regardless of safety, suitability, and health conditions.

Deficiency in education and awareness of play benefits: Poor knowledge is observed among designers, architects, planners, and teachers about the benefits of outdoor play for children and the kinds of places that are desirable for them. Most of the time, designers and planners arrange the environment as it is viewed by an adult instead of a child. 
Poor accessibility: Today, children have fewer chances of traveling to the outdoors on their own. As mentioned by Hillman (1999), when children obtain permission from their parents to explore the outdoor environment by themselves, fewer public spaces are available for them to have social and recreational activities because of the appropriation of streets to traffic and parking. Furthermore, children need to be able to meet their peers and play spontaneously. However, playgrounds that are far from family, peers, and neighbors do not fit into this concept of play. Most apartment buildings do not have any outdoor space that is accessible to children (White and Stoecklin 1998). "There is substantial evidence that children's freedom to independently visit places within their own neighborhood has been decreasing significantly, even over the last generation" (Hillman 1999; Tranter and Doyle 1996).

\section{Rethinking Open Space Provision for Children}

\subsection{Some Design Criteria for an Open Space Provision in Iran}

Overall, a desirable city should meet the needs of all the citizens who live in it. While they are young, children form a significant portion of society, and they learn how to live through play. More importantly, the deficiencies of every city in the world in terms of outdoor play should be addressed. According to previous discussions on urban public space, the following criteria are formulated to ensure the development of an ideal play space for children in Tehran.

Accessibility: To play, children should be able to access suitable outdoor spaces in their immediate environments, such as the home, neighborhood, or school. Accessibility will enable children to move freely and safely through these spaces and connect with their peers.

Local government involvement: When children play together in groups, they engage in different activities with one another; they share cultural practices and in fact build communities through this process. Furthermore, free play in a public space is significant in the development of society and democracy. Although play is an essential part of children's lives, young people do not have any voice, authority, or power to assert their rights in a society. In this situation, the local government should monitor equity in the provision of public spaces for children.

Knowledge sharing: Sharing knowledge about the role of outdoor play in the lives of children and about its long-term effect on them is the responsibility of adults who are responsible for children's welfare, such as parents, teachers, caregivers, city planners, and architects.

Proper design: The design of playgrounds is vital for children in terms of two aspects: first, it should be designed in a way that children can recognize desirable and suitable places where they are eager to play in; and second, playgrounds should promote child development and learning. In the literature, the following key points on the play spaces of children are proposed:

Environmental stimulation: Spaces that offer a variety of challenges and support as well as suggest activities that are essential for children are important in child development. Children improve their abilities through their senses, so the play environment should be able to stimulate the five senses.

Environmental diversity: A fundamental factor in the play space of children is variety. A play space could be regarded in different aspects, such as diversity in the ways of using the environment and various textures with both natural and fabricated materials to enhance the sensation and learning of children. Moreover, this type of public space should be able to offer different situations of social interactions, which clearly define private and public spaces.

Safety: Management of risk and safety is a significant issue in children's playgrounds. According to studies, the presence of a reasonable amount of risk in these environments is needed so that children can test their abilities, enjoy adventures, and explore the world, which could allow children to exercise their power in confronting to the real world with greater responsibility.

Design from the perspective of children: Most of the time, children choose to play elsewhere because many playgrounds have superficial play facilities. By considering the needs and desires of children in the design process, the designers can visualize a suitable playground from the perspective of children.

In the past and currently in many countries, planners have acted independently with little attention given to the needs of children's environment. Thus, research should examine the role of children in urban development and in particular the relationship among children, open play spaces, and the planning process. The environmental needs of children were not and are still not always programmed as planning concerns. For example, the economic urban and structured planning in Iran does not facilitate the development of a child-centered policy, which requires an overall work practice integration that goes beyond pure planning limitations. Studies that can inform 
planners about the needs of children in Tehran are urgently needed.

Sustainability in play provision: Preventing injuries is vital to ensure the suitability and safety of the play environment for children. Therefore, the provision of security mechanisms, technologically advanced facilities, as well as their regular supervision, maintenance, and monitoring are essential in play environments.

\section{Conclusion}

In summary, literature indicates that children need to play outdoors to completely develop various aspects of their personality. A consequence of the indoor-oriented behavior of children is the increasing rates of obesity and sedentary lifestyles, which are undoubtedly harmful to human health. The outdoor environment influences the different aspects of child development by providing opportunities for free or unstructured play every day. Today, communities experiencing urbanization face with its different issues and consequences which push concerns about children's play out of the public debate on policy priorities. In this manner, planners are required to direct the needs, views, and opportunities for children in designing friendly urban environments and finding ways to maintain sufficient resources for this purpose. A main duty of the urban planner is the regulation and control of land use which are limited by broader government policies. Studies show these sources for children outdoor play are shrinking in Tehran and exploring the development of positive policies, further research on open space considerations and appropriate design is needed to promote children's outdoor play in Iran.

\section{Acknowledgement}

The authors would like to express our heartiest thanks to Universiti Kebangsaan Malaysia (Lestari Physical Development Research Group - LPhyD and Evolutionary \& Sustainable Urban Living Research Group- EvoSUL) for supporting this research. Credit also goes to various organizations that assist towards the success of this research, in one way or another.

\section{References}

Ahmed, A. (2005). Children's perception on their living spaces in Dhaka City: a qualitative overview.

Amiri, M. et al. (2013). Parent's and children's judgements about their outdoor environment in relation to children's injuries. Retrieved July 29, 2014, from http://jpma.org.pk/full_article_text.php?article_id=5511

Andersen, R. E. et al. (1998). Relationship of physical activity and television watching with body weight and level of fatness among children: Results from the Third National Health and Nutrition Examination Survey. Jama, 279(12), 938-942. http://dx.doi.org/10.1001/jama.279.12.938

Armitage, M. (2001). The ins and outs of school playground play: children's use of "play places." Play today in the primary school playground: Life, learning and creativity, pp.37-58.

Barnett, L. A. (1990). Developmental benefits of play for children. Journal of Leisure Research.

Bartlett, S. (1999). Children's experience of the physical environment in poor urban settlements and the implications for policy, planning and practice. Environment and Urbanization, 11(2), 63-74. http://dx.doi.org/10.1177/095624789901100207

Bartlett, S. et al. (1999). Cities for Children: Children's Rights, Poverty and Urban Management. ERIC.

Beard, J. G., \& Ragheb, M. G. (1980). Measuring leisure satisfaction. Journal of leisure Research, 12(1), 20-33.

Behzadfar, M. (2009). Urban projects and programs. Tehran. Nashr publication.

Bertaud, A. (2003). Tehran spatial structure: Constraints and opportunities for future development. Ministry of Housing and Urban Development, Tehran.

Blakely, K. S. (1994). Parents' conceptions of social dangers to children in the urban environment. Children's Environments, 16-25.

Boesen, L. (1999). Toys in the townscape. The Danish Design Centre Journal, 134-139.

Booth, M. L. (2000). Questions-4 What proportion of Australian children are sufficiently physically active? Medical Journal of Australia, 173(3), S6.

Carlin, J. B. et al. (1997). Walking to school and traffic exposure in Australian children. Australian and New Zealand journal of public health, 21(3), 286-292. http://dx.doi.org/10.1111/j.1467-842X.1997.tb01701.x

CDC, C. for D. control and prevention, 2009. Prevention (CDC). (2008). Nutrition for Everyone: Polyunsaturated Fats and Monounsaturated Fats.

CDC, C. for D.C. and P., 2003. Physical activity levels among children aged 9-13 years--United States, 2002. 
MMWR. Morbidity and mortality weekly report, 52(33), p.785.

CDC, C. for D.C. and P., 2008. Youth risk behavior surveillance-United States, 2007. MMWR Surveill Summ, 57(4), pp.1-131.

Chawla, L., \& Heft, H. (2002). Children's competence and the ecology of communities: a functional approach to the evaluation of participation. Journal of environmental psychology, 22(1), 201-216. http://dx.doi.org/10.1006/jevp.2002.0244

Chawla, L., \& Unesco. (2002). Growing up in an urbanising world, Earthscan London.

Chen, M. (1994). The Smart Parent's Guide to Kids' TV. ERIC.

Clements, R. (2004). An Investigation, 5(1), pp.68-80.

Coffin, G., \& Williams, M. (1989). Children's Outdoor Play in the Built Environment. London: National Children's Play and Recreation Unit.

Dale, D., Corbin, C. B., \& Dale, K. S. (2000). Restricting opportunities to be active during school time: do children compensate by increasing physical activity levels after school? Research Quarterly for Exercise and Sport, 71(3), 240-248. http://dx.doi.org/10.1080/02701367.2000.10608904

Dietze, B., \& Crossley, B. (2000). Young children and outdoor play. Loyalist College: Belleville, Ont.

Hall, T. (2010). Life and death of the Australian backyard.

Hart, R. (2002). Containing children: some lessons on planning for play from New York City. Environment and Urbanization, 14(2), 135-148. Retrieved August 17, 2013, from http://eau.sagepub.com/cgi/doi/10.1177/095624780201400211

Hart, R. A. (1992). Children's participation: From tokenism to citizenship. UNICEF Innocenti Research Centre.

Hillman, M. (1999). Curbing children's social and emotional development: An unrecognized outcome of parental fears. Journal of Contemporary Health, 8(Winter), 38-42.

Hughes, B. (1990). Children's play-a forgotten right. Environment and Urbanization, 2(2), 58-64. http://dx.doi.org/10.1177/095624789000200207

Jafari, H. R., Salehi, E., \& Sadeghi Naeini, H. (2011). Playground safety: an approach to environmental planning. Journal of Environmental Studies, 36(56), 4.

Lobo, F., \& Olson, E. (2000). Leisure services and children at-risk: against all odds. Journal of Park and Recreation Administration, 18(1), 5-18.

McKendrick, J. H., Bradford, M. G., \& Fielder, A. V. (2000). Time for a party! Making sense of the commercialisation of leisure space for children. Children's Geographies: playing, living, learning. London: Routledge.

Memik, N. H. (2004). An evaluation of the changing approaches to children's play spaces.

Mergen, B. (1975). The discovery of children's play. American Quarterly, 399-420. http://dx.doi.org/10.2307/2712329

Moore, G. T. (1987). The physical environment and cognitive development in child-care centers. Springer. http://dx.doi.org/10.1007/978-1-4684-5227-3_3

Moore, R. C. (1990). Childhood's domain: play and place in child development. MIG communications.

Pellegrini, A. D. (2005). Research and Policy on Children 's Play.

Pellegrini, A. D., \& Smith, P. K. (1998). Physical activity play: The nature and function of a neglected aspect of play. Child development, 69(3), 577-598. http://dx.doi.org/10.1111/j.1467-8624.1998.tb06226.x

Powell, S. (2009). The Value of Play: Constructions of Play in Government Policy in England. Children \& Society, 23(1), 29-42. http://dx.doi.org/10.1111/j.1099-0860.2008.00137.x

Rehmani, R. (2008). Childhood injuries seen at an emergency department. Childhood. Retrieved July 29, 2014, from http://www.jpma.org.pk/full_article_text.php?article_id=1341

Reilly, J. J. et al. (2004). Total energy expenditure and physical activity in young Scottish children: mixed longitudinal study. The Lancet, 363(9404), 211-212. http://dx.doi.org/10.1016/S0140-6736(03)15331-7

Riggio, E. (2002). Child friendly cities: good governance in the best interests of the child. Environment and Urbanization, 14(2), 45-58. http://dx.doi.org/10.1177/095624780201400204 
Rippe, J. M., Weissberg, R. P., \& Seefeldt, V. (1993). The purpose of play: a framework for improving childhood health and psychological and physical development. Med Exerc Nutr Health, 2, 225-231.

Risotto, A. (2002). Projects and Policies for Childhood in Italy. Culture, Environment Action and Sustainability, Gottingen, pp.299-313.

Saremi, H., Ebrahimpour, M., \& Saeedi, S. M. (2012). Analyzing of Reduction Process of Urban Open Spaces in Process of Cities Development with Emphasis on Crisis Management in Tehran Metropolis. Journal of Sustainable Development, 5(9), 130. http://dx.doi.org/10.5539/jsd.v5n9p130

Sawyer, T. H. (2002). Facilities planning for health, fitness, physical activity, recreation and sports: Concepts and applications. Sagamore Publishing.

Siddiqui, M. M. R. (1990). Recreational Facilities in Dhaka City: A Study of Existing Parks and Open Spaces. MURP Thesis, Submitted to the Urban and Regional Planning, Bangladesh University of Engineering and Technology (BUET), Dhaka, Bangladesh.

Talebi, M. R., \& Ardakani, A. S. (2011). Investigation of Tehran green Space changes and its role in air pollution Using LANDSAT images from 1980-2010.

Tehran-Municipality. (2011). Tehran statictical year book 2011-2012. In T. Municipality (Ed.). Tehran: Tehran municipality.

Titman, W., \& McGill, I. (1992). Play, playtime and playgrounds: key issues for teachers, supervisors and governors of primary schools. LTL/WWF UK.

Tomkinson, G. R. et al. (2003). Secular trends in the performance of children and adolescents (1980-2000). Sports Medicine, 33(4), 285-300. http://dx.doi.org/10.2165/00007256-200333040-00003

Townsend, A., \& Taub, N. Y. U. (2004). Eric Paulos Intel Research Ken Anderson Intel Research.

Tranter, P., \& Doyle, J. (1996). Reclaiming the residential street as play space. International Play Journal, 4, 81-97.

Trost, S. G. (2005). Discussion paper for the development of recommendations for children's and youth's participation in health promoting physical activity.

Valentine, G. (2004). Public space and the culture of childhood. Ashgate Aldershot.

Vincent, S. D. et al. (2003). Activity levels and body mass index of children in the United States, Sweden, and Australia. Medicine and science in sports and exercise, 35(8), 1367-1373. http://dx.doi.org/10.1249/01.MSS.0000079024.40014.91

Ward, C. (1978). The child in the city. Society, 15(4), 84-91. http://dx.doi.org/10.1007/BF02694719

White, R., \& Stoecklin, V. (1998). Children's outdoor play \& learning environments: Returning to nature.

Wing, R. R. et al. (2001). Behavioral science research in diabetes lifestyle changes related to obesity, eating behavior, and physical activity. Diabetes care, 24(1), 117-123. http://dx.doi.org/10.2337/diacare.24.1.117

Wridt, P. J. (2004). An historical analysis of young people's use of public space, parks and playgrounds in New York City. Children Youth and Environments, 14(1), 86-106.

Zaradic, P. A., \& Pergams, O. R. W. (2007). Videophilia: Implications for childhood development and conservation. Journal of Developmental Processes, 2(1), 130-144.

Zimmet, P. Z., McCarty, D. J., \& de Courten, M. P. (1997). The global epidemiology of non-insulin-dependent diabetes mellitus and the metabolic syndrome. Journal of Diabetes and its Complications, 11(2), 60-68. http://dx.doi.org/10.1016/S1056-8727(96)00090-6

\section{Copyrights}

Copyright for this article is retained by the author(s), with first publication rights granted to the journal.

This is an open-access article distributed under the terms and conditions of the Creative Commons Attribution license (http://creativecommons.org/licenses/by/3.0/). 